\title{
A GH51 a-L-arabinofuranosidase from Talaromyces leycettanus strain JCM12802 that selectively drives synergistic lignocellulose hydrolysis
}

Tao Tu* (1), Xiaoli Li, Kun Meng, Yingguo Bai, Yuan Wang, Zhenxing Wang, Bin Yao and Huiying Luo*

\begin{abstract}
Background: The development of sustainable technologies for plant cell wall degradation greatly depends on enzymes with hydrolytic activities against carbohydrates. The waste by-products of agricultural cereals are important biomass sources because they contain large amounts of saccharides. Achieving efficient debranching and depolymerization are two important objectives for increasing the utilization of such renewable bioresources. GH51 a-L-arabinofuranosidases are important in biomass pretreatment because they act synergistically with other enzymes during hemicellulose hydrolysis.

Results: A GH51 a-L-arabinofuranosidase from Talaromyces leycettanus JCM12802 was heterologously expressed in Pichia pastoris GS115 and characterized. The recombinant a-L-arabinofuranosidase, TIAbf51, showed an optimum temperature and $\mathrm{pH}$ of $55-60{ }^{\circ} \mathrm{C}$ and 3.5-4.0, respectively, and remained stable at $50^{\circ} \mathrm{C}$ and pH 3.0-9.0. TIAbf51 showed a higher catalytic efficiency $\left(5712 \mathrm{mM}^{-1} \mathrm{~s}^{-1}\right)$ than most fungal a-L-arabinofuranosidases towards the substrate 4-nitrophenyl-a-L-arabinofuranoside. Moreover, TIAbf51 preferentially removed 1,2- or 1,3-linked arabinofuranose residues from arabinoxylan and acted synergistically with the bifunctional xylanase/cellulase TcXyn10A at an activity ratio of 5:1. The highest yields of arabinose and xylooligosaccharides were obtained when TIAbf51 was added after TCXyn10A or when both enzymes were added simultaneously. High-performance anion-exchange chromatography analyses showed that (i) arabinose and xylooligosaccharides with low degrees of polymerization (DP1-DP5) and (ii) arabinose and xylooligosaccharides (DP1-DP3) were the major hydrolysates obtained during the hydrolysis of sodium hydroxide-pretreated cornstalk and corn bran, respectively.
\end{abstract}

Conclusions: In contrast to other fungal GH51 a-L-arabinofuranosidases, recombinant TIAbf51 showed excellent stability over a broad pH range and high catalytic efficiency. Moreover, TIAbf51 acted synergistically with another hemicellulase to digest arabino-polysaccharides. These favorable enzymatic properties make TIAbf51 attractive for biomass pretreatment and biofuel production.

Keywords: Talaromyces leycettanus JCM12802, a-L-Arabinofuranosidase, Saccharification, Oligosaccharides

\footnotetext{
*Correspondence: tutao@caas.cn; luohuiying@caas.cn

Key Laboratory for Feed Biotechnology of the Ministry of Agriculture,

Feed Research Institute, Chinese Academy of Agricultural Sciences, No. 12

Zhongguancun South Street, Beijing 100081, People's Republic of China
} 


\section{Background}

The large amounts of by-products produced during the machining of agricultural cereals, such as straw, stover, and husks, are important resources for biofuel production [1]. Lignocellulosic biomass, as the most abundant renewable bioresource, is derived from plant cell walls and is mainly comprised of cellulose, hemicellulose, and lignin, among which cellulose and hemicellulose are the first and second most abundant polysaccharides on Earth $[2,3]$. Because hemicellulose is concatenated with cellulose via hydrogen bonds and is chemically cross-linked with lignin, it is naturally resistant to digestion by cellulases. Thus, hemicellulose degradation can help cellulases access cellulose, resulting in more efficient cellulose utilization $[4,5]$. Therefore, a more efficient means of enzymatic hemicellulose depolymerization in the biofuel and biorefinery industries is desired.

The main component of hemicellulose is xylan, which is composed of covalently $\beta$-1,4-linked $D$-xylose residues that can be attached by substituents at different side chains such as L-arabinose, D-glucuronic acid, 4-O-methyl-D-glucuronic acid, ferulic acid, $p$-coumaric acid, and acetyl groups [6]. Thus, thorough degradation or modification of xylan requires the combined activities of several different enzymes, including the core enzymes endo- $\beta$-1,4-D-xylanase (EC 3.2.1.8) and $\beta$-1,4-D-xylosidase (EC 3.2.1.37) along with other accessory enzymes, such as $\alpha$-L-arabinofuranosidase (Abf, EC 3.2.1.55). However, complex substrates with branched side chains are not easily degraded. Thus, an accessory enzyme, such as Abf, is valuable for industrial applications such as plant residue biotransformation, food processing, and pulp bleaching.

Abfs are normally found in six glycoside hydrolase (GH) families: GH2, GH3, GH43, GH51, GH54, and GH62. These families are divided based on sequence similarity and differentiated based on their modes of action against substrates with different linkages [7]. Generally, Abf members catalyze the hydrolysis of arabinose from the non-reducing ends of different arabinose-containing polysaccharides and oligosaccharides $(\alpha-1,2-, \alpha-1,3-$, and $\alpha-1,5-;[8])$. Based on their substrate specificity, Abfs are grouped into three types (A, B, and C). Type A Abfs preferentially act on arabinooligosaccharides, while type $B$ Abfs preferentially act on both polysaccharides and arabinooligosaccharides. Both type A and B Abfs show activity towards $p$-nitrophenyl- $\alpha$-L-arabinofuranoside. In contrast, type C Abfs specifically degrade arabinosidic linkages within arabinoxylans [9]. Fungal GH51 Abfs from Aspergillus awamori IFO4033 [10], Aspergillus nidulans FGSC A4 [11], Aspergillus niger CBS 513.88 [12], Chrysosporium lucknowense C1 [13], and Penicillium chrysogenum 31B [14] have been characterized. These Abfs are active against arabinoxylans and arabino-containing saccharides and release arabinose, although they show much higher activity towards branched arabinan compared to debranched arabinan [15]. These applaudable enzymatic characteristics make GH51 Abfs interesting for synergistic use with other hemicellulases to completely degrade hemicelluloses.

Talaromyces leycettanus strain JCM12802 produces high levels of cellulases (such as $\beta$-glucanase [16] and $\beta$-mannanase [17]), hemicellulases (such as xylanase [18]), and pectinases (such as polygalacturonase [19]). In this study, we identified an Abf gene (Tlabf51) of GH51 in T. leycettanus JMC12802, which was overexpressed in Pichia pastoris GS115 and characterized. Next, we studied the synergistic activities of TlAbf51 and the bifunctional xylanase/cellulase TcXyn10A (from Thermoascus crustaceus JCM12803; [20]) in the hydrolysis of watersoluble wheat arabinoxylan. The synergistic effects on the degradation of sodium hydroxide-pretreated cornstalk and corn bran were also investigated.

\section{Results}

Gene cloning and sequence analysis

An Abf, designated here as TlAbf51, was isolated from the thermophilic T. leycettanus JCM12802. The fulllength chromosomal and cDNA sequences of Tlabf51 (GenBank accession no. MK734377) consisted of 2362 and 1887 base pairs, respectively. Eight introns interrupted the cDNA sequence and the mature protein contained 628 residues with a calculated molecular mass of $67.2 \mathrm{kDa}$. Seven putative $\mathrm{N}$-glycosylation sites and four $O$-glycosylation sites were identified within the deduced TlAbf51 sequence by NetNGlyc Server analysis. The deduced amino acid sequence of TlAbf51 shares the highest identity of $79.9 \%$ with the glycoside hydrolase of Aspergillus ellipticus CBS 707.79 and 28.1\% sequence identity with the known crystal structure of Abf from Bifidobacterium longum ( $2 \mathrm{Y} 2 \mathrm{~W})$, demonstrating that Tlabf51 is a novel Abf gene.

\section{Expression and purification of recombinant TIAbf51}

Recombinant TlAbf51 was expressed in the P. pastoris GS115 system and secreted into the culture medium. Significant Abf activities were observed in shake tube cultures against 4-nitrophenyl- $\alpha$-L-arabinofuranoside. After large-scale cultivation and purification, the electrophoretic homogeneity of recombinant TlAbf51 was determined by sodium dodecyl sulfate-polyacrylamide gel electrophoresis (SDS-PAGE) analysis (Additional file 1). To verify the target protein, liquid chromatography-electrospray ionization tandem mass spectrometry (LC-ESIMS) was conducted to identify the band. Five peptides corresponding to the sequence of recombinant TlAbf51 
and no other peptides were detected (Additional file 2). These results confirmed the purity of the band and the identity of $T l$ Abf51.

\section{Biochemical characterization}

For enzyme characterization, 4-nitrophenyl- $\alpha$-larabinofuranoside was used as a substrate. TlAbf51 was optimally active at $\mathrm{pH} 3.5-4.0$ and showed $>40 \%$ of its peak activity at $\mathrm{pH} 2.5-5.0$ (Fig. 1a). The enzyme exhibited good stability over a wide $\mathrm{pH}$ range, maintaining $>70 \%$ of its maximum activity after incubation at $\mathrm{pH}$ 3.0-9.0, $37{ }^{\circ} \mathrm{C}$ for $1 \mathrm{~h}$ (Fig. 1a). The optimal temperature for $\mathrm{TlAbf5} 1$ activity was $55-60{ }^{\circ} \mathrm{C}$ and the enzyme was active over a temperature range of $20-70{ }^{\circ} \mathrm{C}$ at $\mathrm{pH}$ 3.5 (Fig. 1b). The enzyme showed good thermostability, and $>90 \%$ residual activity was retained after $30-\mathrm{min}$ incubation at $50{ }^{\circ} \mathrm{C}$ (Fig. 1b). The $T_{50}$ value of TlAbf51, i.e., the temperature corresponding to $50 \%$ of the peak
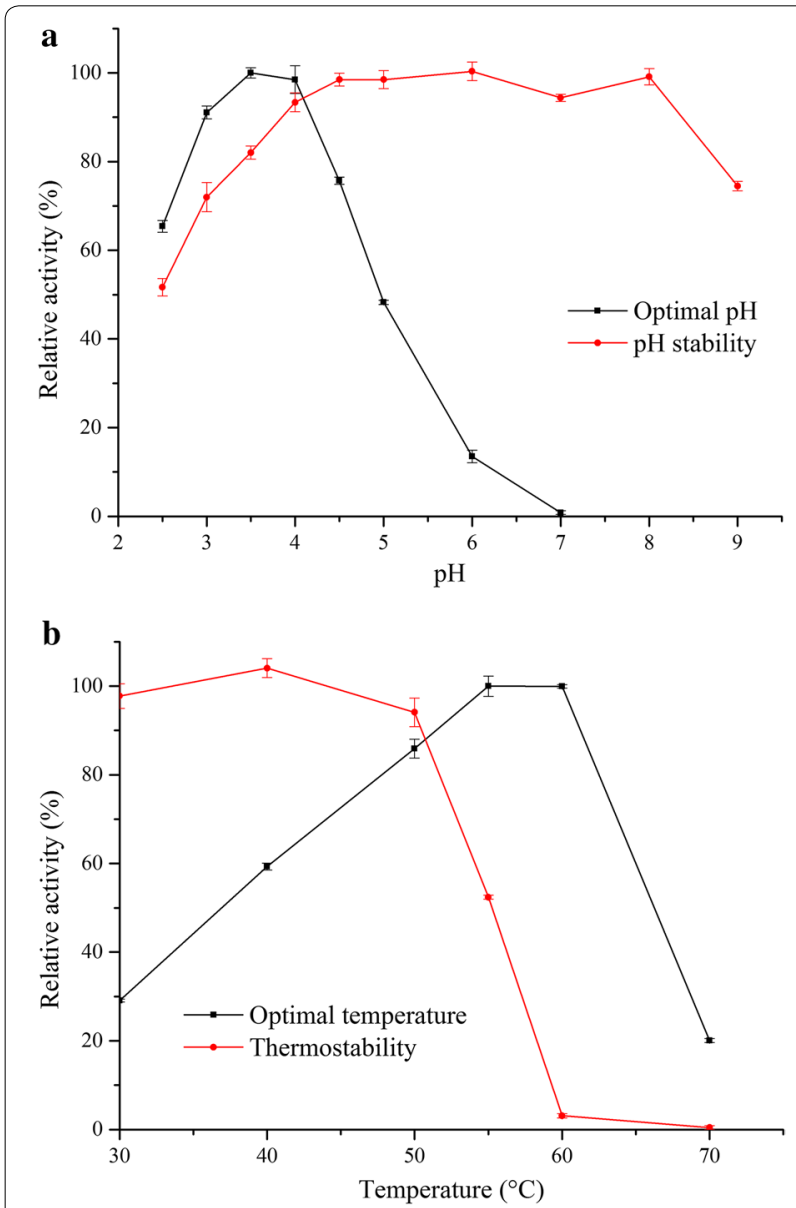

Fig. 1 Effects of $\mathrm{pH}(\mathbf{a})$ and temperature (b) on purified recombinant TIAbf51. The activity of TIAbf51 was measured under the indicated conditions and presented as a percentage of the maximum level activity following a 30-min incubation period, was determined to be $55^{\circ} \mathrm{C}$.

\section{Substrate specificity and kinetic parameters}

Several substrates were used to test the substrate specificity of TlAbf51. For 4-nitrophenyl-glycoside substrates, TlAbf51 showed activity only towards 4 -nitrophenyl- $\alpha-\mathrm{L}-$ arabinofuranoside and 4-nitrophenyl- $\beta$-D-xylopyranoside. The relative ratio of activity towards two substrates was 300:1. Under standard conditions, the specific activity of TlAbf51 towards 4-nitrophenyl- $\alpha$-L-arabinofuranoside was $1068 \pm 8.4 \mathrm{U} / \mathrm{mg}$. The $K_{\mathrm{m}}, V_{\max }$, and $k_{\text {cat }}$ values of TlAbf51 were determined to be $0.28 \pm 0.01 \mathrm{mM}$, $1428 \pm 10.7 \mu \mathrm{mol} \mathrm{min}{ }^{-1} \mathrm{mg}^{-1}$, and $1600 \mathrm{~s}^{-1}$, respectively. The $k_{\text {cat }} / K_{\mathrm{m}}$ value was $5712 \mathrm{mM}^{-1} \mathrm{~s}^{-1}$.

For polysaccharide substrates, TlAbf51 was highly active against water-soluble wheat arabinoxylan (Fig. 2a). After incubation for $12 \mathrm{~h}, 475.4 \mathrm{mg} / \mathrm{L}$ of arabinose was obtained as the final product (Fig. 2b). Moreover, the enzyme exhibited much higher activity towards sugar beet arabinan than against the debranched sugar beet arabinan (releasing 480.7 and $64.4 \mathrm{mg} / \mathrm{L}$ arabinose, respectively), indicating that $T l \mathrm{Abf5} 1$ preferentially acted on 1,2- or 1,3-linked arabinan residues debranched as side chains rather than linear $\alpha-1,5-\mathrm{L}$-arabinan.

\section{Synergistic effect of TIAbf51 and TCXyn10A on wheat arabinoxylan degradation}

To improve the efficiency of xylan hydrolysis, the hydrolysis efficiency of water-soluble wheat arabinoxylan by TlAbf51 and bifunctional xylanase/cellulase TcXyn10A, tested individually or in combination, were analyzed by high-performance anion-exchange chromatography and pulsed amperometric detection (HPAEC-PAD). Compared to the hydrolysis products generated by TlAbf51 or TcXyn10A alone, all enzyme combinations showed significant synergistic effects on wheat arabinoxylan degradation, producing markedly higher levels of arabinose and xylooligosaccharides. After 12-h incubation of TlAbf51 with $0.5 \%$ wheat arabinoxylan, the concentration of arabinose reached $184.3 \mathrm{mg} / \mathrm{L}$ (Fig. 3a). When incubated with $0.5 \mathrm{U} T c \mathrm{Xyn} 10 \mathrm{~A}$, the levels of xylooligosaccharides (xylose, xylobiose, and xylotriose) reached $451.4 \mathrm{mg} / \mathrm{L}$, although small amounts of arabino-branched xylooligosaccharides were observed (Fig. 3b). Adding TlAbf51 first, followed by $T c X y n 10 \mathrm{~A}$, resulted in a significant increase in the production of arabinose and xylooligosaccharides $(963.6 \mathrm{mg} / \mathrm{L})$ as compared to adding $T c \mathrm{X}$ yn10A alone (Fig. 3c). When TcXyn10A was added first, followed by $T l \mathrm{Abf51}$, larger amounts of arabinose, xylotetraose, and xylopentaose were released $(1455.9 \mathrm{mg} / \mathrm{L}$; Fig. 3d). The greatest synergy was found after simultaneously incubating wheat arabinoxylan with TlAbf51 and 

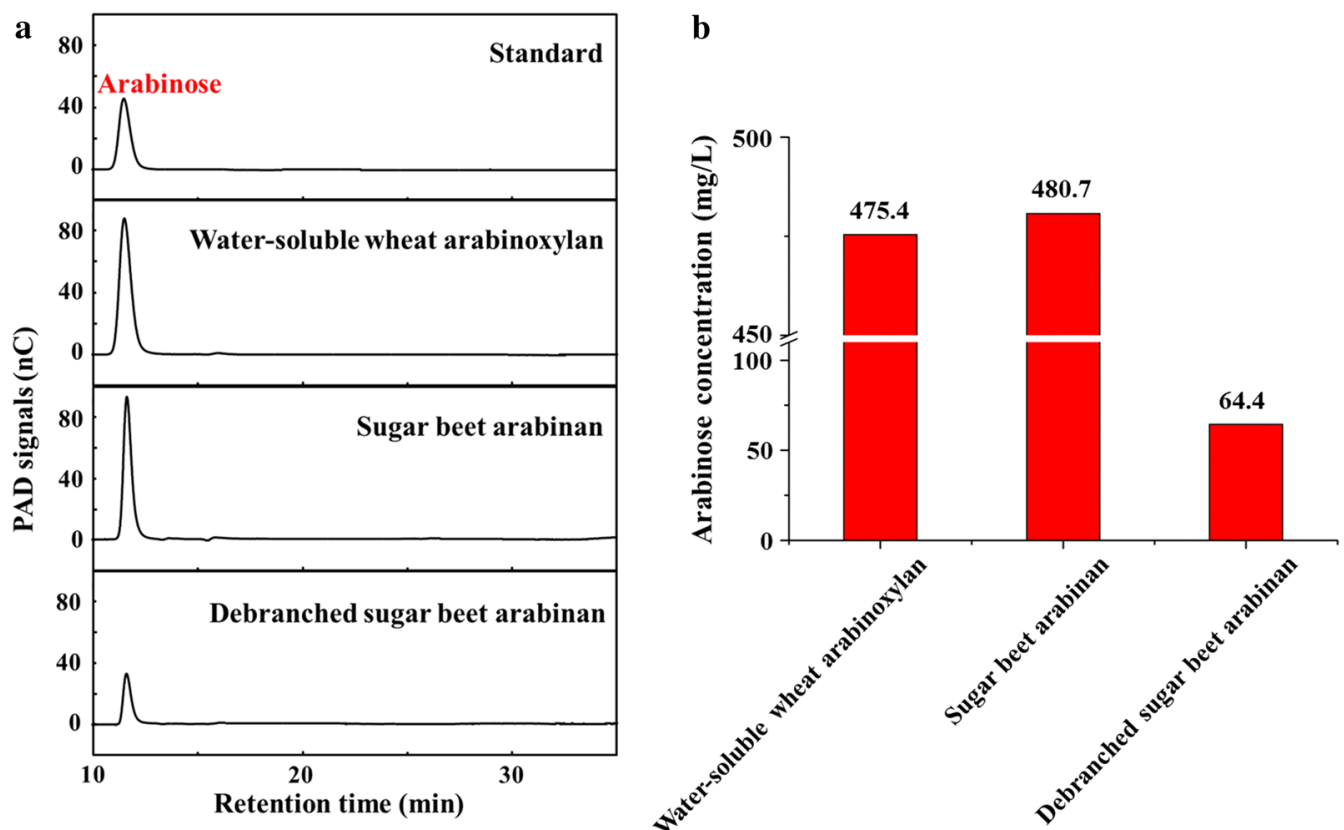

Fig. 2 Hydrolytic activity of TIAbf51 on arabinose-based polysaccharide substrates. a Water-soluble wheat arabinoxylan, sugar beet arabinan, and debranched sugar beet arabinan were incubated with TIAbf5 1 at $37^{\circ} \mathrm{C}$ for $12 \mathrm{~h}$. The resulting hydrolysates were detected by HPAEC-PAD. b The amount of arabinose released by TIAbf51 with each of the three substrates based on the chromatographic peak areas of arabinose shown in $\mathbf{a}$ Sugar release was quantified (right panel) using a standard curve for each oligosaccharide

TcXyn10A, with the concentration of released oligosaccharides reaching $1480.5 \mathrm{mg} / \mathrm{L}$ (Fig. 3e).

To further examine the synergistic effects of TlAbf51 and TcXyn10A, the released reducing saccharides from water-soluble wheat arabinoxylan by simultaneous incubation with both enzymes were analyzed by the 3,5-dinitrosalicylic acid (DNS) method. TlAbf51 treatment alone liberated reducing sugars from wheat arabinoxylan (Fig. 4a). Higher concentrations of reducing sugars were observed when TlAbf51 and TcXyn10A were combined at different activity ratios compared to treatment with $T c$ Xyn10A alone. These results suggest that TlAbf51 acted synergistically with $T c$ Xyn $10 \mathrm{~A}$. The highest degree of synergy was obtained when TcXyn10A and TlAbf51 were added at an enzyme-activity ratio of 1:5, corresponding to a synergy score of 1.47 (Fig. 4b).

\section{Hydrolysis of sodium hydroxide-pretreated cornstalk and corn bran with TIAbf51 and TCXyn10A}

Using sodium hydroxide-pretreated cornstalk and corn bran as respective substrates, TlAbf51 and TcXyn10A were further tested for their ability to hydrolyze lignocellulose. The reducing sugars in the hydrolysis products obtained after 3-h treatment of sodium hydroxide-pretreated cornstalk and corn bran with TlAbf51 and TcXyn10A individually or combined at the activity ratio of $1: 5$ ( 0.5 and $2.5 \mathrm{U})$ were analyzed by DNS method
(Fig. 5a). TlAbf51 and TcXyn10A showed significant synergistic effects. For this enzyme-activity ratio, the maximum amounts of oligosaccharides (corresponding to $37.9 \%$ hydrolysis of the cornstalk) were obtained after a 24-h hydrolysis of cornstalk (Fig. 5b; Additional file 3). Xylotriose was the major oligosaccharide produced, followed by arabinose, xylobiose, and low amounts of xylose, xylotetraose, and xylopentaose. Interestingly, the enzymes dramatically increased the oligosaccharide levels to $2.8 \mathrm{~g} / \mathrm{L}$ (corresponding to $56.2 \%$ hydrolysis of the corn bran) during the hydrolysis of corn bran (Fig. 5c; Additional file 4). Among the released sugars, the most abundant were arabinose, xylose, xylobiose, and xylotriose, which differed from the hydrolysis products of cornstalk. After $36-\mathrm{h}$ hydrolysis, $1.65 \mathrm{~g} / \mathrm{L}$ arabinose was obtained from corn bran, which was $\sim 2.8$-fold more than that obtained from cornstalk.

\section{Effect of TIAbf51 on arabinose release from cellulosic biomass}

Cornstalk and corn bran were selected as cellulosic biomass, and the effect of TlAbf51 and the commercial complex enzyme ULTRAFLO XL on arabinose release was compared. As shown in Additional files 5 and 6, the effect of TlAbf51 on arabinose release from cornstalk was comparable with that of ULTRAFLO XL, but significantly weaker than that of ULTRAFLO XL in corn bran. Our 

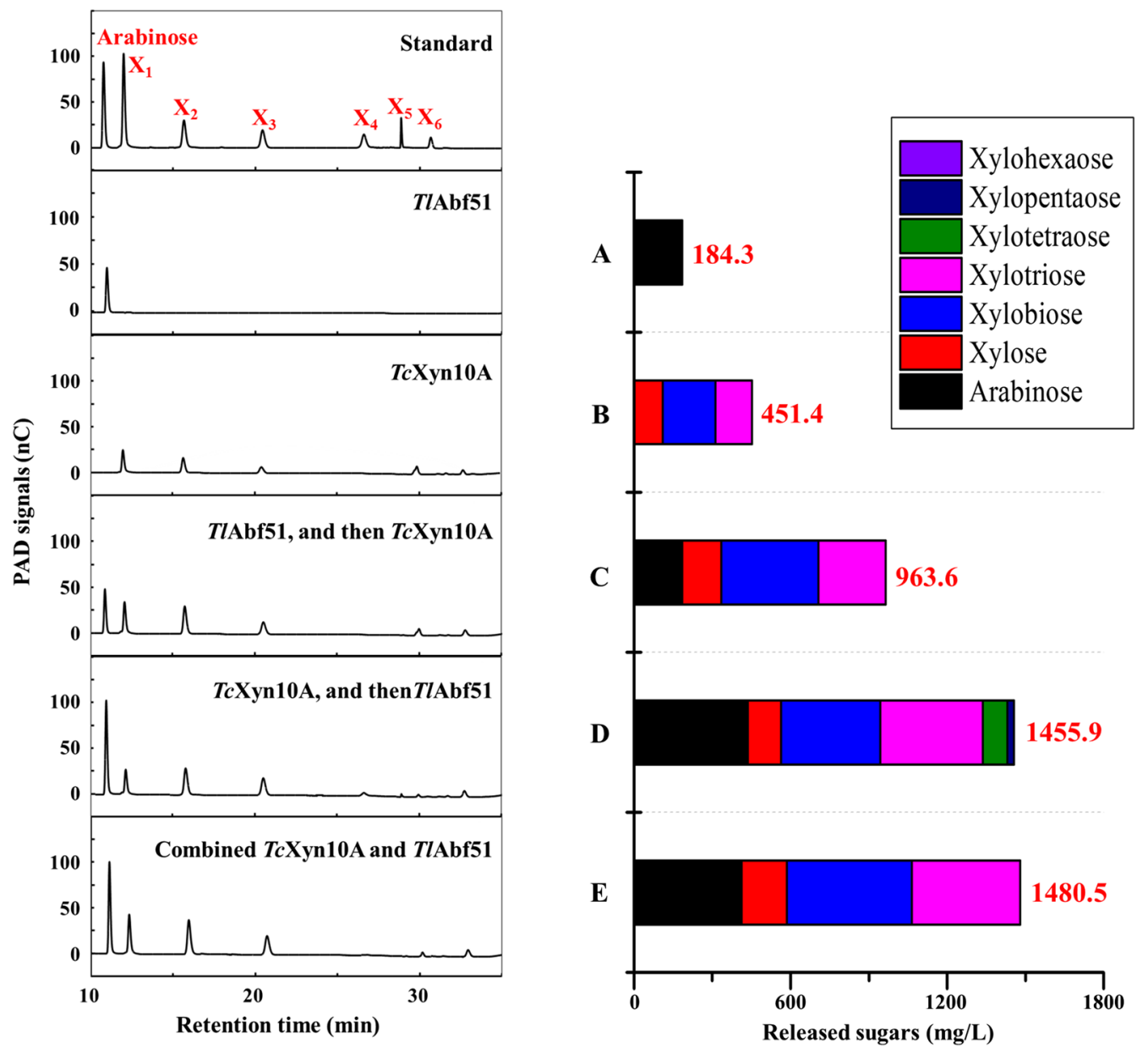

Fig. 3 Combined activities of TIAbf51 with the bifunctional xylanase/cellulase TCXyn10A for water-soluble wheat arabinoxylan degradation. We hydrolyzed $0.5 \%$ wheat arabinoxylan using different enzyme combinations, including a reaction with a TIAbf51 alone, b TCXyn10A alone, c sequential reactions of TIAbf51 and TCXYn10A for $12 \mathrm{~h}$, respectively, $\mathbf{d}$ sequential reactions of TCXyn10A and TIAbf51 for $12 \mathrm{~h}$, respectively, and $\mathbf{e}$ simultaneous incubation with TIAbf51 and TcXyn10A for $12 \mathrm{~h}$. The hydrolysates were analyzed by HPAEC-PAD

study is in agreement with others showing the synergistic effect of Abf and cellulose/hemicellulose. The Novozymes ULTRAFLO XL has not only Abf, but also xylanase, pentosanase, cellulase, and $\alpha$-amylase activity. Probably this explains the greater efficiency of the Novozymes ULTRAFLO XL observed in our study.

\section{Discussion}

In the past decade, improvements in the utilization of renewable energy resources have attracted great interest worldwide [21]. The use of waste by-products of agricultural cereals as important sources of biomass helps avoid competition between energy and food crops [1]. For example, the by-product stream from wheat contains $\sim 66 \%$ arabinoxylan by weight, of which $\sim 74-91 \%$ by weight is water-soluble [22]. To increase the utilization of arabinoxylan in the waste by-products of agricultural cereals, it is important to efficiently degrade the abundant arabinoxylan into its monosaccharides, arabinose and xylose. In this study, a GH51 Abf TlAbf51 was identified from T. leycettanus JCM12802, and its high expression was achieved in $P$. pastoris GS115. As shown in Table 1, the optimal $\mathrm{pH}$ (3.5-4.0) for this enzyme was similar to that for Abf from A. kawachii [10], but lower than those for Abfs from C. lucknowense C1 (5.0; [13]), P. chrysogenum 31B (5.0; [14]) and Penicillium purpurogenum (5.0; [23]). TlAbf51 exhibited good stability over a wider $\mathrm{pH}$ range (3.0-9.0) than the other fungal GH51 Abfs. Examination of the optimal temperature and thermostability showed that $T l A b f 51$ exceeded the general properties of formerly reported counterparts that were more active at $40-60{ }^{\circ} \mathrm{C}$ and stable at $50{ }^{\circ} \mathrm{C}$. However, compared to the other characterized fungal Abfs, TlAbf51 exhibited 


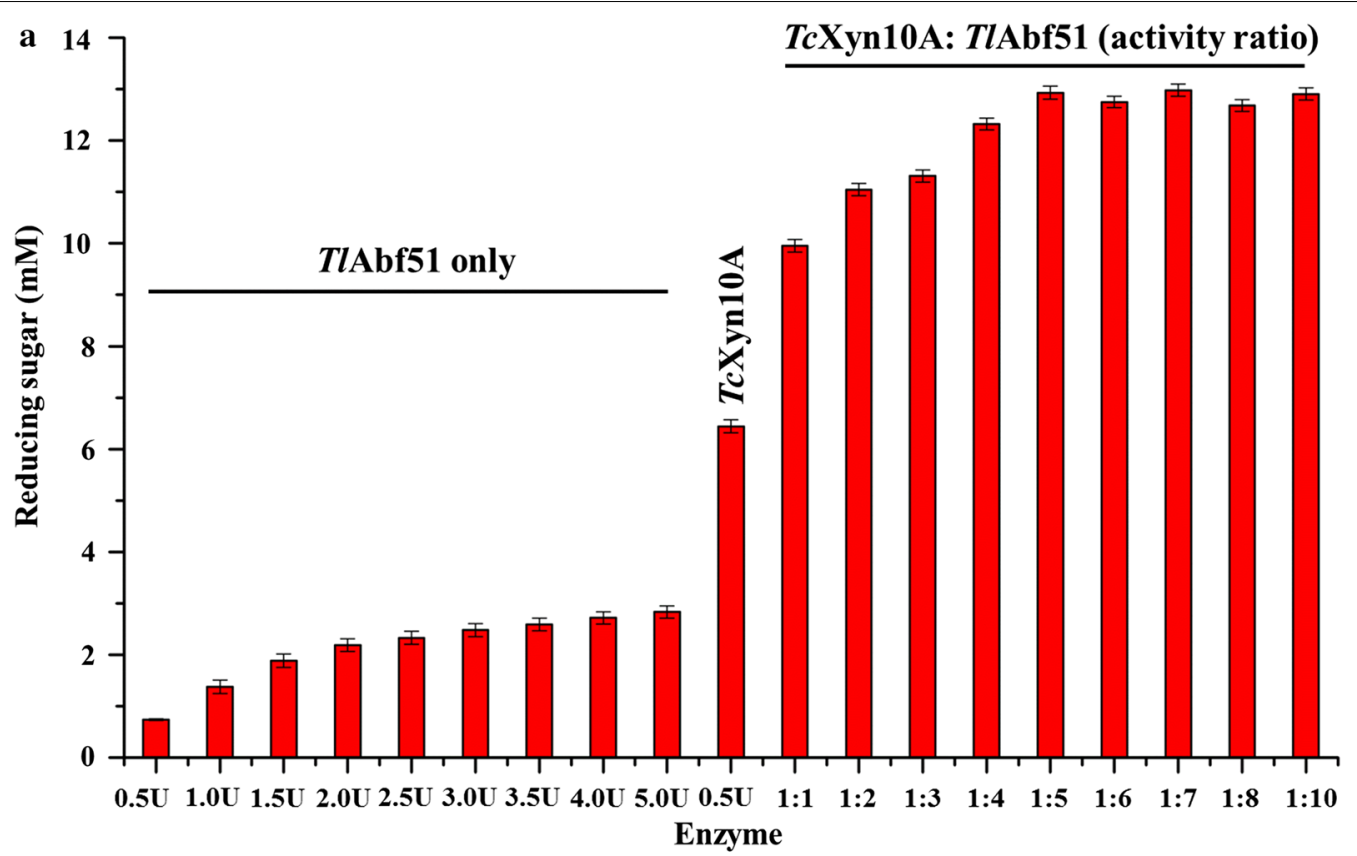

b

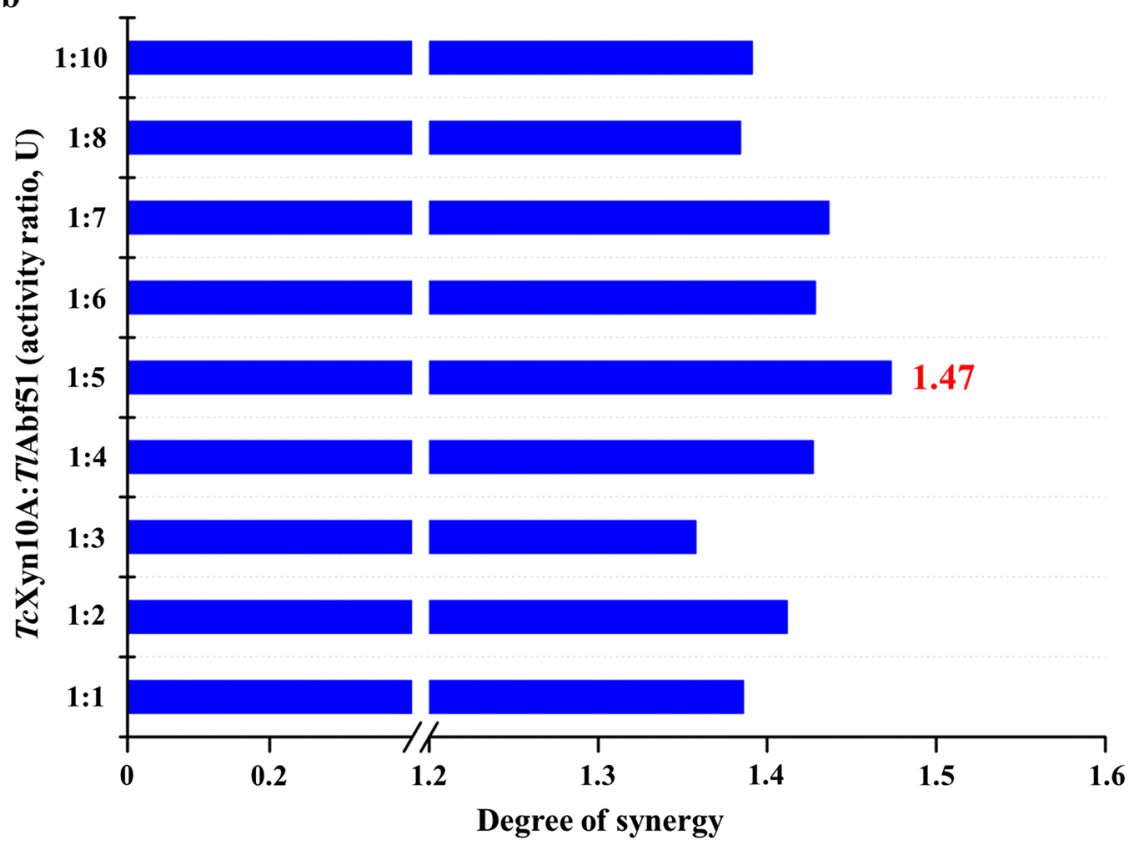

Fig. 4 Synergistic effects of T/Abf51 with the bifunctional xylanase/cellulase TCXyn10A. a Reducing sugars obtained by a reaction with TIAbf51 or TCXyn10A, singly and in combination with different enzyme-activity ratios. $\mathbf{b}$ Degree of synergy observed after the combined reaction with TCXYn10A and TIAbf51. The synergic degree was defined as the amounts of saccharides released from the simultaneous activities of both enzymes to the sum of those released by both enzymes individually

significantly greater catalytic efficiency $\left(k_{\mathrm{cat}} / K_{\mathrm{m}}\right.$ value; approximately 125 -fold higher) towards 4 -nitrophenyl$\alpha$-L-arabinofuranoside. These characteristics make TlAbf51 one of the most feasible candidates for industrial applications.
In terms of its substrate specificity, $T l \mathrm{Abf} 51$ was highly specific for $\alpha$-L-arabinofuranosyl linkages, as observed for homologous enzymes. TlAbf51 produced arabinose as the sole hydrolysis product towards sugar beet arabinan and debranched sugar beet arabinan, but the amount 

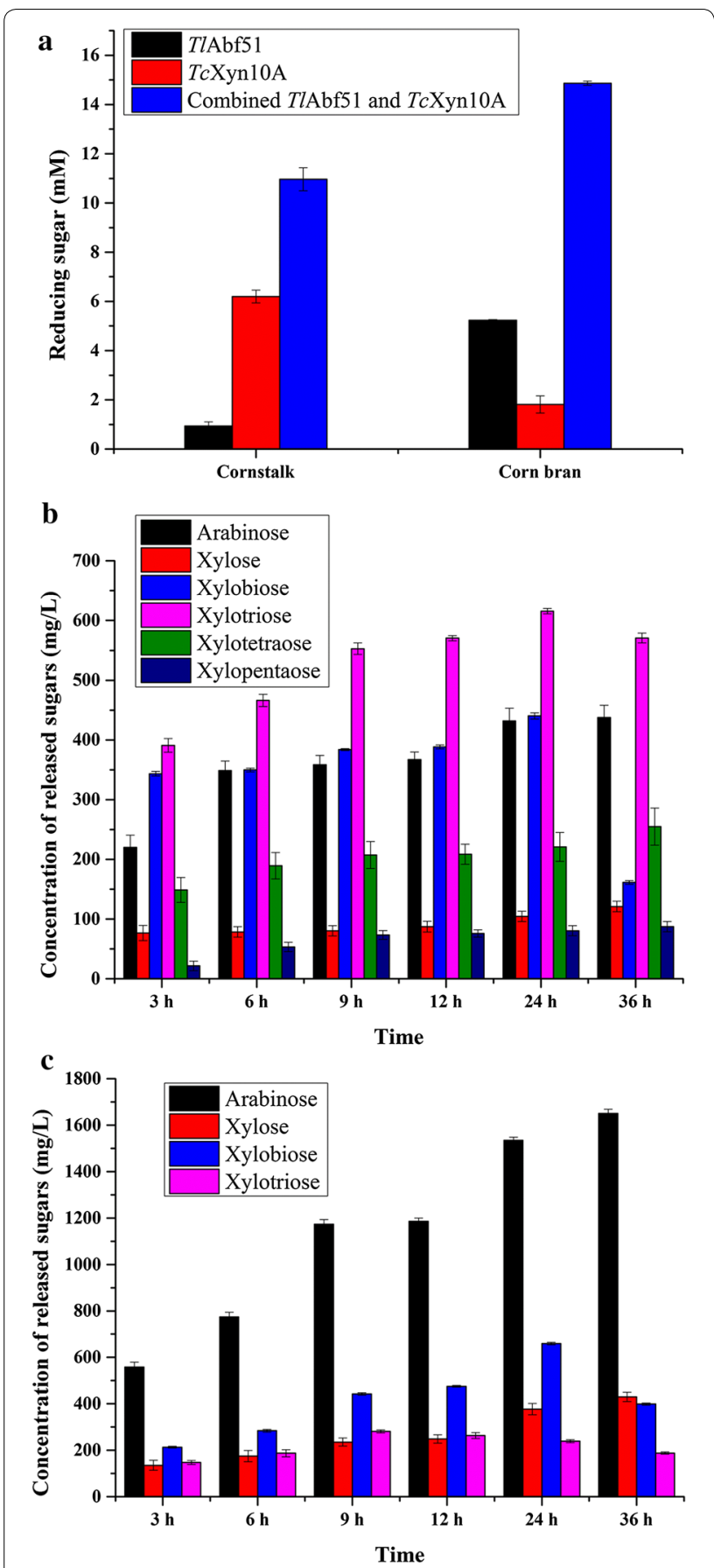

Fig. 5 Hydrolysis of sodium hydroxide-pretreated cornstalk and corn bran with TIAbf51 and TCXyn10A. a Reducing sugars obtained by a reaction with TIAbf51 or TcXyn10A individually or in combination at an enzyme-activity ratio of 1:5 for $3 \mathrm{~h}$. Oligosaccharides were obtained by degradation of hydroxide-pretreated cornstalk (b) and corn bran (c) in synergistic hydrolysis assays performed for 3, 6, 9, 12, 24 and $36 \mathrm{~h}$

liberated from the former was significantly higher than from the latter $(480.7$ vs. $64.4 \mathrm{mg} / \mathrm{L})$. This suggests that TlAbf51 is a type B Abf, given that type B Abfs are more active against polymeric arabinoxylan, which is singly or doubly substituted with 1,2- or 1,3-linked arabinose residues [24]. Two recent reports described bacterial GH51 Abfs isolated from Alicyclobacillus sp. A4 (AcAbf51A; [25]) and Paenibacillus sp. THS1 (THSAbf; [26]) that displayed both Abf and xylanase activities. However, 12-h digestion of water-soluble wheat arabinoxylan with TlAbf51 generated arabinose as the sole product (Fig. 3a), and no xylooligosaccharides were produced. To date, no studies have demonstrated that fungal GH51 Abfs exhibit xylanase activity. The deduced amino acid sequence of TlAbf51 shares $23.5 \%$ similarity with those of AcAbf51A and THSAbf (Additional file 7). Bouraoui et al. [25] demonstrated the functional importance of the catalytic dyad (Glu177 and Glu296) and hydrophobic residue Trp101 located on the $\beta 2 \alpha 2$ loop in THSAbf; the corresponding residues in TlAbf51 are Gln199, Pro354, and Gly120, respectively. These results indicate that the function of fungal $\mathrm{Abf}$ is distinct from that of bacterial Abf.

To improve the hydrolysis efficiency for xylan, combinations of TlAbf51 and bifunctional xylanase/cellulase TcXyn10A were examined both sequentially and simultaneously. Significant synergy occurred in all sequential reactions performed with different enzyme-activity ratios, with the highest arabinose and xylooligosaccharides production observed when TlAbf51 was added after TcXyn10A or when both enzymes were added simultaneously (Fig. 3). Similar observations have been reported for AcAbf51A [24]. These results indicate that efficient degradation of wheat arabinoxylan occurred by first interrupting the main chains with TcXyn10A, followed by branch separation with TlAbf51. The underlying mechanism may involve cleavage of the main chains by TcXyn10A which can make arabinobranched xylooligosaccharides more accessible to TlAbf51, while removal of the side chains of arabino-branched xylooligosaccharides by TlAbf51 can also improve the degradation efficiency of arabino-branched xylooligosaccharides by TcXyn10A [27]. Based on this, we tested nine enzymeactivity ratios with TcXyn10A and TlAbf51 and compared their performances in wheat arabinoxylan degradation. The combination of TcXyn10A and TlAbf51 at an enzymeactivity ratio of 1:5 was determined to be the most efficient (Fig. 4). It is well-known that it is difficult to degrade complex substrates such as wheat arabinoxylan which contains large amounts of arabinoxylan [28, 29]. Arabinobranched polysaccharides and xylooligosaccharides were efficiently debranched by TlAbf51. Interestingly, similar activity ratios between core and accessory enzymes utilized for natural substrate degradation have been reported, such as those for polygalacturonase and pectin methylesterase from Penicillium oxalicum for pectin degradation [30], as well as endoglucanase and cellobiohydrolase from Irpex lacteus for cellulose degradation [31]. Therefore, the 
Table 1 Property comparison of TIAbf51 with other fungal Abfs of GH51

\begin{tabular}{|c|c|c|c|c|c|c|c|}
\hline Microorganism & MW (kDa) & pH optimum & $\begin{array}{l}\text { Temperature } \\
\text { optimum }\left({ }^{\circ} \mathrm{C}\right)\end{array}$ & pH stability & Thermostability & $k_{\text {cat }} / K_{\mathrm{m}}(/ \mathrm{mM} / \mathrm{s})^{\mathrm{a}}$ & References \\
\hline T. leycettanus JCM12802 & 67.2 & $3.5-4.0$ & $55-60$ & $3.0-9.0$ & $\begin{array}{l}>90 \% \text { activity at } 50^{\circ} \mathrm{C} \\
\quad \text { for } 30 \mathrm{~min}\end{array}$ & 5712 & This study \\
\hline Aspergillus kawachii & $\begin{array}{l}80 \text { for } A k a b f A \\
62 \text { for } A k a b f B\end{array}$ & 4.0 & 55 & $3.0-7.0$ & Stable at $55^{\circ} \mathrm{C}$ & ND & {$[10]$} \\
\hline $\begin{array}{l}\text { Chrysosporium luc- } \\
\text { knowense } \mathrm{C} 1\end{array}$ & 71 & 5.0 & 40 & ND & ND & ND & {$[13]$} \\
\hline $\begin{array}{l}\text { Penicillium chrysogenum } \\
\text { 31B }\end{array}$ & $\begin{array}{l}71 \text { for } A F Q 1 \\
52 \text { for AFS1 }\end{array}$ & 5.0 & 50 & $\begin{array}{l}\text { 4.0-8.0 for AFQ1 } \\
3.0-7.0 \text { for AFS1 }\end{array}$ & $\begin{array}{l}>80 \% \text { activity at } 50^{\circ} \mathrm{C} \\
\text { for } 1 \mathrm{~h} \\
\text { Completely inactivated } \\
\text { at } 60^{\circ} \mathrm{C}\end{array}$ & $\begin{array}{l}16.7 \text { for } \mathrm{AFQ1} \\
44.9 \text { for } \mathrm{AFS} 1\end{array}$ & [14] \\
\hline $\begin{array}{l}\text { Penicillium purpuroge- } \\
\text { num }\end{array}$ & 70 & 5.0 & 60 & ND & $\begin{array}{l}\sim 50 \% \text { activity at } 50^{\circ} \mathrm{C} \\
\quad \text { for } 2 \mathrm{~h}\end{array}$ & 24.8 & {$[23]$} \\
\hline
\end{tabular}

ND not determined

a Catalytic efficiency $\left(k_{\mathrm{cat}} / K_{\mathrm{m}}\right.$ value) was determined using 4-nitrophenyl-a-L-arabinofuranoside as the substrate

ideal enzyme-activity ratio (between core and accessory enzymes) for maximizing hydrolysis yields and minimizing enzyme usage in biomass degradation may be approximately 1:5. Using this enzyme-activity ratio, 1.9 and $2.8 \mathrm{~g} / \mathrm{L}$ of oligosaccharides were obtained after 24-h hydrolysis of cornstalk and corn bran, respectively.

\section{Conclusions}

An Abf from T. leycettanus JCM12802 was heterologously expressed and characterized. The acidity of TlAbf51 exhibited good stability over a broad $\mathrm{pH}$ range (3.0-9.0), and TlAbf51 exhibited significantly greater catalytic efficiency than other fungal GH51 Abfs. The enzyme preferentially removed 1,2- or 1,3-linked arabinose residues from arabinoxylan and acted synergistically with the bifunctional xylanase/cellulase TcXyn10A. Simultaneous addition of TcXyn10A and TlAbf51 resulted in the highest degradation efficiency of wheat arabinoxylan at an enzyme-activity ratio of 1:5. Additionally, this enzyme cocktail exhibited efficient degradation of sodium hydroxide-pretreated cornstalk and corn bran. This study demonstrated the efficient enzymatic saccharification of lignocellulose and suggests the high potential of using TlAbf51 in the field of biomass pretreatment.

\section{Methods}

\section{Strains, vectors, and media}

Talaromyces leycettanus JCM12802 (Japan Collection of Microorganisms RIKEN BioResource Center, Tsukuba, Japan) was cultured in medium containing lignocellulose as the sole carbon source at $45{ }^{\circ} \mathrm{C}$ for 3 days [32]. Escherichia coli strain Trans I-T1 and the pEASY-T3 vector (TransGen, Beijing, China) were employed for DNA manipulation. P. pastoris GS115 and the pPIC9 vector
(Invitrogen, Carlsbad, CA, USA) were used for heterologous gene expression.

\section{Cloning Tlabf51}

The full-length Tlabf51 gene was identified in the genome of $T$. leycettanus strain JCM12802 (whole genome sequenced, unpublished). After growth for 3 days in induction medium, mycelia were collected to extract total RNA, which were further purified using the SV Total RNA isolation system (Promega, Madison, WI, USA). First-strand cDNA was generated with the ReverTra Ace- $\alpha-{ }^{\circledR}$ Kit (TOYOBO, Osaka, Japan) using purified total RNA as a template. Subsequently, the full-length cDNA of Tlabf51 was amplified by high-fidelity PCR using specific primers (no signal peptide coding sequence based on SignalP 4.0 prediction. F: $5^{\prime}$-ATGAAAACC CTCCCCGCATTGGCCGGCGGC-3'; and R: 5'-CTA AGACACGGCCAGCACCGCAACAGCCCA-3'). Next, the specific gene fragment was cloned into the pEasy-T3 vector for sequencing.

\section{Heterologous expression and purification}

The cDNA fragment encoding Tlabf51 was amplified from the pEasy-T3-Tlabf51 plasmid using primers with flanking restriction sites (pF: 5'-TTGAATTCATGAAA ACCCTCCCCGCATTGG-3'; and pR: 5'-TAGCGGCC GCCTAAGACACGGCCAGCACCG-3'; EcoRI and NotI sites underlined, respectively). The PCR product was gelpurified, digested with corresponding restriction endonucleases, and then linked into the vector pPIC9. After verification by DNA sequencing, BglII was used to linearize the recombinant plasmid followed by electroporation to transform P. pastoris GS115 competent cells. Based on enzymatic activities in shake tubes, the positive transformants were screened, and the transformant with 
the highest Abf activity was selected for fermentation following as described by Yang et al. [27].

To remove cell debris and undissolved materials, the induced cultures were collected and centrifuged at $12,000 \times g$ for $10 \mathrm{~min}$ at $4{ }^{\circ} \mathrm{C}$. The cell-free culture supernatant was concentrated with a $10-\mathrm{kDa}$ molecular weight cutoff Vivaflow 200 membrane (Vivascience, Hannover, Germany), followed by desalination in $20 \mathrm{mM}$ McIlvaine buffer (pH 3.0) using a 5-mL HiPrep desalting column. Next, the desalted sample was loaded onto a HiTrap SP HP 5-mL FPLC column (GE Healthcare), which had been pre-equilibrated with McIlvaine buffer. To obtain the target proteins, a linear gradient of $\mathrm{NaCl}(0-1.0 \mathrm{M})$ in the same buffer was used. Fractions showing enzyme activities were eluted and subjected to SDS-PAGE. The protein concentration was measured by the Bradford assay via determining the absorbance at $595 \mathrm{~nm}$. Bovine serum albumin was used as the standard.

\section{Enzyme assay}

Abf activity was determined according to the method of Yang et al. [27], with some modifications. Briefly, standard reactions contained $250 \mu \mathrm{L}$ of $1 \mathrm{mM} 4$-nitrophenyl- $\alpha$ $\mathrm{L}$-arabinofuranoside and $250 \mu \mathrm{L}$ properly diluted enzyme solution in $0.1 \mathrm{M}$ Mcllvaine buffer ( $\mathrm{pH}$ 3.5). After incubation at $50{ }^{\circ} \mathrm{C}$ for $10 \mathrm{~min}, 1.5 \mathrm{~mL} 1 \mathrm{M} \mathrm{Na}_{2} \mathrm{CO}_{3}$ was added to terminate the reaction. The absorption at $405 \mathrm{~nm}$ was determined to detect the amount of $p$-nitrophenol released. All reactions were performed in triplicate. One unit of Abf activity was defined as the amount of enzyme that released $1 \mu \mathrm{mol}$ of 4-nitrophenyl/min under standard conditions.

Xylanase activity was measured using the DNS method [33] with D-xylose as the standard. The reaction system containing $900 \mu \mathrm{L} \mathrm{1 \% (w/v)} \mathrm{water-soluble} \mathrm{wheat} \mathrm{arabi-}$ noxylan (Megazyme) in $0.1 \mathrm{M}$ McIlvaine buffer ( $\mathrm{pH}$ 3.5) and $100 \mu \mathrm{L}$ of an appropriately diluted enzyme solution was incubated at $55^{\circ} \mathrm{C}$ for $10 \mathrm{~min}$ followed by the addition of $1.5 \mathrm{~mL}$ DNS reagent, and then the concentration of reducing sugars was determined by measuring the absorption at $540 \mathrm{~nm}$. Each reaction was performed in triplicate. One unit of xylanase activity was defined as the amount of enzyme that released reducing sugars equivalent to $1 \mu \mathrm{mol}$ of $\mathrm{D}$-xylose/min under the assay conditions.

\section{Biochemical characterization}

The $\mathrm{pH}$ optima in terms of the activity of purified recombinant TlAbf51 was measured in 10-min reactions performed at $55{ }^{\circ} \mathrm{C}$ in $0.1 \mathrm{M}$ Mcllvaine buffer over a $\mathrm{pH}$ range of 2.5-7.0. To estimate enzyme stability at different $\mathrm{pH}$ levels (0.1 M Mcllvaine buffer, $\mathrm{pH} 2.5-7.0 ; 0.1 \mathrm{M}$ Tris- $\mathrm{HCl}, \mathrm{pH}$ 8.0-9.0), residual activities were measured under standard conditions after the enzyme was preincubated in buffer without substrate at $37^{\circ} \mathrm{C}$ for $1 \mathrm{~h}$. To determine the optimum reaction temperature, 10-min reactions were performed at different temperatures ranging from 30 to $70{ }^{\circ} \mathrm{C}$ at $\mathrm{pH} 3.5$. The thermal stability of $T l \mathrm{Abf5} 1$ was investigated by measuring residual activities under standard conditions after pre-incubation of the enzyme for $30 \mathrm{~min}$ at the same temperatures (as described above) in the absence of substrate.

\section{Substrate specificity and kinetic parameters}

The substrate activities of TlAbf51 on 4-nitrophenylglycoside substrates (Sigma; including 4-nitrophenyl- $\alpha$ L-arabinofuranoside, 4-nitrophenyl- $\beta$-D-xylopyranoside, 4-nitrophenyl- $\alpha$-D-galactopyranoside, 2 -nitrophenyl- $\beta$-Dgalactopyranoside, 4-nitrophenyl- $\alpha$-D-glucopyranoside, 4-nitrophenyl- $\alpha$-L-arabinopyranoside, and p-nitrophenylacetate) were measured by determining the Abf activity under the standard conditions described above. The substrate activities of $T l \mathrm{Abf} 51$ on polysaccharide substrates (Megazyme; including water-soluble wheat arabinoxylan, sugar beet arabinan, and debranched sugar beet arabinan) were detected by HPAEC-PAD using a $250 \times 3 \mathrm{~mm}$ CarboPac PA200 guard column (Thermo Fisher Scientific, Waltham, MA, USA) as previously reported [34]. Arabinose and xylooligosaccharides (xylose, xylobiose, xylotriose, xylotetraose, xylopentaose, and xylohexaose) were used as standards.

Enzyme-kinetics assays were determined at $55{ }^{\circ} \mathrm{C}$ for $5 \mathrm{~min}$ in $0.1 \mathrm{M}$ Mcllvaine buffer (pH 3.5) with $0.1-5 \mathrm{mM}$ 4-nitrophenyl- $\alpha$-L-arabinofuranoside as substrate. The constants $\left(K_{\mathrm{m}}\right.$ and $V_{\max }$ values) of TlAbf51 were plotted by fitting the data to a Michaelis-Menten plot using GraphPad Prism software (GraphPad, Inc., La Jolla, CA, USA).

\section{Synergistic hydrolysis of wheat arabinoxylan with TIAbf51 and TCXyn $10 \mathrm{~A}$}

The bifunctional xylanase/cellulase TcXyn10A from $T$. crustaceus JCM12803 [20] is an excellent, economically viable candidate for the enzymatic degradation of plant cell wall polysaccharides for biofuels and bio-based chemicals. Thus, its synergistic activity with TlAbf51 in the hydrolysis of wheat arabinoxylan was investigated. To study the hydrolytic activities of $T l \mathrm{Abf} 51$ and TcXyn10A on water-soluble wheat arabinoxylan, the hydrolysis products were analyzed by HPAEC-PAD as described above. All reaction systems containing $900 \mu \mathrm{L}$ of $0.5 \%$ $(\mathrm{w} / \mathrm{v})$ substrate and $100 \mu \mathrm{L}$ of enzyme(s) $(0.5 \mathrm{U}$ each of TlAbf51 and/or TcXyn10A) were performed at $37{ }^{\circ} \mathrm{C}$ in $0.1 \mathrm{M}$ Mcllvaine buffer ( $\mathrm{pH} 4.0$ ). After 12-h incubation, the reactions were terminated by heat denaturation by boiling for $10 \mathrm{~min}$. The second enzyme solution was then 
added for the sequential reactions. The reaction system with substrate but without any enzyme was defined as the blank control. The resulting hydrolysis products were analyzed by the HPAEC-PAD method.

To determine the extent of synergy, different enzymeactivity ratios were used, and the production of reducing ends from water-soluble wheat arabinoxylan was measured. Experimentally, $0.5 \mathrm{U}$ of TcXyn10A was combined with TlAbf51 at enzyme-activity ratios ranging from 1:1 to $1: 10$ and incubated with $0.5 \%$ wheat arabinoxylan. The hydrolysis reactions were carried out in Mcllvaine buffer at $\mathrm{pH} 4.0$ and $37^{\circ} \mathrm{C}$ for $12 \mathrm{~h}$, and then the reactions were terminated by heat denaturation by boiling for $10 \mathrm{~min}$. The amount of reducing sugars released was determined using the DNS method.

\section{Synergistic hydrolysis of sodium hydroxide-pretreated cornstalk and corn bran}

Cornstalk and corn bran pretreatments were performed according to Zhuo et al. [5]. The milled cornstalk and corn bran samples were autoclaved at $120{ }^{\circ} \mathrm{C}$ for $1 \mathrm{~h}$ with $1 \%(\mathrm{w} / \mathrm{v})$ sodium hydroxide at a $10 \%$ ratio $(\mathrm{w} / \mathrm{v})$. Next, pretreated samples were filtered through eight layers of gauze, and then washed multiple times with distilled water, followed by drying in a thermotank at $40{ }^{\circ} \mathrm{C}$ to achieve a constant weight for subsequent saccharification experiments. Synergistic hydrolysis of sodium hydroxide-pretreated cornstalk and corn bran was studied in $0.1 \mathrm{M}$ Mcllvaine buffer ( $\mathrm{pH} 4.0$ ) containing pretreated samples $(0.5 \%, \mathrm{w} / \mathrm{v}), 0.5 \mathrm{U}$ of $T c \mathrm{X}$ yn10A, and $2.5 \mathrm{U}$ of $T l \mathrm{Abf} 51$. The reaction system with substrate but without any enzyme was defined as the blank control. Hydrolysis proceeded for various durations, and the samples were collected and analyzed by HPAEC-PAD.

\section{Comparison of TIAbf51 with a commercial enzyme}

The effect of $T l A b f 51$ on arabinose release from cornstalk and corn bran was compared with that of a commercial multi-active $\beta$-glucanase from Novozymes (ULTRAFLO XL). Firstly, the Abf activity of TlAbf51 and ULTRAFLO $\mathrm{XL}$ was evaluated under the same conditions $(\mathrm{pH} 4.0$ and $55^{\circ} \mathrm{C}$ ). Then, mixtures of cellulosic biomass sample (cornstalk or corn bran; 0.5\%, w/v) and $2.5 \mathrm{U}$ enzyme (TlAbf51 or ULTRAFLO XL) in $0.1 \mathrm{M}$ McIlvaine buffer ( $\mathrm{pH} 4.0$ ) were incubated at $37^{\circ} \mathrm{C}$ for $12 \mathrm{~h}$. The released arabinose was assessed by HPAEC-PAD.

\section{Additional files}

Additional file 1. SDS-PAGE analysis of the purified recombinant TIAbf51. Lanes: $M$, the standard protein molecular weight markers; 1 , the purified recombinant T/Abf51.

Additional file 2. . LC-ESI-MS/MS analysis of the purified recombinant TIAbf51.

Additional file 3. Time course of hydrolysis of sodium hydroxide pretreated cornstalk by simultaneously addition of TCXyn10A and TIAbf51 at activity ratio of $1: 5(0.5 \mathrm{U}$ and $2.5 \mathrm{U}) .1$, the oligosaccharides standards; $2-7$, the hydrolysate with enzyme treatment for $3 \mathrm{~h}, 6 \mathrm{~h}, 9 \mathrm{~h}, 12 \mathrm{~h}, 24 \mathrm{~h}$ and $36 \mathrm{~h}$, respectively.

Additional file 4. Time course of hydrolysis of sodium hydroxide pretreated corn bran by simultaneously addition of TCXyn10A and TIAbf51 at activity ratio of 1:5 (0.5 $\mathrm{U}$ and $2.5 \mathrm{U})$. 1, the oligosaccharides standards; $2-7$, the hydrolysate with enzyme treatment for $3 \mathrm{~h}, 6 \mathrm{~h}, 9 \mathrm{~h}, 12 \mathrm{~h}, 24 \mathrm{~h}$ and $36 \mathrm{~h}$, respectively.

Additional file 5. The effect of TIAbf51 on arabinose release from cornstalk was compared with that of a commercial multi-active $\beta$-glucanase from Novozymes (ULTRAFLO XL).

Additional file 6 . The effect of TIAbf51 on arabinose release from corn bran was compared with that of a commercial multi-active $\beta$-glucanase from Novozymes (ULTRAFLO XL).

Additional file 7. Amino acid sequence alignment of TIAbf51 from Talaromyces leycettanus JCM12802 with other two GH51 Abfs from Alicyclobacillus sp. A4 (AcAbf51A) and Paenibacillus sp. THS1 (THSAbf).

\section{Abbreviations}

DP: degrees of polymerization; Abf: a-L-arabinofuranosidase; GH: glycoside hydrolase; SDS-PAGE: sodium dodecyl sulfate-polyacrylamide gel electrophoresis; LC-ESI-MS: liquid chromatography-electrospray ionization tandem mass spectrometry; $K_{m}$ : Michaelis constant; $V_{\max }$ : maximum reaction rate; $k_{\text {cat }}$ : turnover number; HPAEC-PAD: high-performance anion-exchange chromatography and pulsed amperometric detection.

\section{Authors' contributions}

TT designed the experiments, analyzed the data and wrote the manuscript. $H L$ revised the manuscript critically for important intellectual content. $X L$ and KM performed the enzyme production and activity assay. ZW performed the enzymatic saccharification. YB and YW performed the data processing and interpretation. BY participated in revising the manuscript. All authors read and approved the final manuscript.

\section{Funding}

This study was supported by grants from the National Key R\&D Program of China (2016YFD0501409-02), the Chinese Academy of Agricultural Science and Technology Innovation Project (CAAS-XTCX2016011-01) and the National Chicken Industry Technology System of China (CARS-41).

\section{Availability of data and materials}

All data generated or analyzed during this study are included in this published article and its Additional files.

\section{Ethics approval and consent to participate}

This article does not contain any studies with human participants or animal performed by any of the authors.

\section{Competing interests}

The authors declare that they have no competing interests.

Received: 8 April 2019 Accepted: 10 August 2019

Published online: 19 August 2019 


\section{References}

1. Cheng X, Huang Z, Wang Z, Ma C, Chen S. A novel on-site wheat straw pretreatment method: enclosed torrefaction. Bioresour Technol. 2019;281:48-55

2. Shrestha S, Fonoll X, Khanal SK, Raskin L. Biological strategies for enhanced hydrolysis of lignocellulosic biomass during anaerobic digestion: current status and future perspectives. Bioresour Technol. 2017;245:1245-57.

3. Krasznai DJ, Champagne Hartley R, Roy HM, Champagne P, Cunningham MF. Compositional analysis of lignocellulosic biomass: conventional methodologies and future outlook. Crit Rev Biotechnol. 2018:38(2):199-217.

4. Li H, Wu H, Xiong L, Chen X, Wang C, Qi G, Huang C, Guo H, Luo M, Liu J, Long M, Chen X. The hydrolytic efficiency and synergistic action of recombinant xylan-degrading enzymes on xylan isolated from sugarcane bagasse. Carbohydr Polym. 2017;175:199-206.

5. Zhuo R, Yu H, Qin X, Ni H, Jiang Z, Ma F, Zhang X. Heterologous expression and characterization of a xylanase and xylosidase from white rot fungi and their application in synergistic hydrolysis of lignocellulose. Chemosphere. 2018;212:24-33.

6. Pereira CS, Silveira RL, Dupree P, Skaf MS. Effects of xylan side-chain substitutions on xylan-cellulose interactions and implications for thermal pretreatment of cellulosic biomass. Biomacromolecules. 2017;18(4):1311-21

7. Hoffmam ZB, Oliveira LC, Cota J, Alvarez TM, Diogo JA, Neto Mde O, Citadini AP, Leite VB, Squina FM, Murakami MT, Ruller R. Characterization of a hexameric exo-acting GH51 a-L-arabinofuranosidase from the mesophilic Bacillus subtilis. Mol Biotechnol. 2013;55(3):260-7.

8. Wilkens C, Andersen S, Dumon C, Berrin JG, Svensson B. GH62 arabinofuranosidases: structure, function and applications. Biotechnol Adv. 2017:35(6):792-804

9. Shinozaki A, Kawakami T, Hosokawa S, Sakamoto T. A novel GH43 a-L-arabinofuranosidase of Penicillium chrysogenum that preferentially degrades single-substituted arabinosyl side chains in arabinan. Enzyme Microb Technol. 2014;58-59:80-6.

10. Koseki T, Okuda M, Sudoh S, Kizaki Y, Iwano K, Aramaki I, Matsuzawa H. Role of two a-L-arabinofuranosidases in arabinoxylan degradation and characteristics of the encoding genes from shochu koji molds, Aspergillus kawachii and Aspergillus awamori. J Biosci Bioeng. 2003;96(3):232-41.

11. Galagan JE, Calvo SE, Cuomo C, Ma L, Wortman JR, Batzoglou S, Lee SI, Baştürkmen M, Spevak CC, Clutterbuck J, Kapitonov V, Jurka J, Scazzocchio C, Farman M, Butler J, Purcell S, Harris S, Braus GH, Draht O, Busch S, D'Enfert C, Bouchier C, Goldman GH, Bell-Pedersen D, Griffiths-Jones S, Doonan JH, Yu J, Vienken K, Pain A, Freitag M, Selker EU, Archer DB, Peñalva MA, Oakley BR, Momany M, Tanaka T, Kumagai T, Asai K, Machida M, Nierman WC, Denning DW, Caddick M, Hynes M, Paoletti M, Fischer R, Miller B, Dyer P, Sachs MS, Osmani SA, Birren BW. Sequencing of Aspergillus nidulans and comparative analysis with $A$. fumigatus and $A$. oryzae. Nature. 2005:438(7071):1105-15.

12. Pel HJ, de Winde JH, Archer DB, Dyer PS, Hofmann G, Schaap PJ, Turner G, de Vries RP, Albang R, Albermann K, Andersen MR, Bendtsen JD, Benen JA, van den Berg M, Breestraat S, Caddick MX, Contreras R, Cornell M, Coutinho PM, Danchin EG, Debets AJ, Dekker P, van Dijck PW, van Dijk A, Dijkhuizen L, Driessen AJ, d'Enfert C, Geysens S, Goosen C, Groot GS, de Groot PW, Guillemette T, Henrissat B, Herweijer M, van den Hombergh JP, van den Hondel CA, van der Heijden RT, van der Kaaij RM, Klis FM, Kools HJ, Kubicek CP, van Kuyk PA, Lauber J, Lu X, van der Maarel MJ, Meulenberg R, Menke H, Mortimer MA, Nielsen J, Oliver SG, Olsthoorn M, Pal K, van Peij NN, Ram AF, Rinas U, Roubos JA, Sagt CM, Schmoll M, Sun J, Ussery D, Varga J, Vervecken W, van de Vondervoort PJ, Wedler H, Wösten HA, Zeng AP, van Ooyen AJ, Visser J, Stam H. Genome sequencing and analysis of the versatile cell factory Aspergillus niger CBS 513.88. Nat Biotechnol. 2007;25(2):221-31.

13. Pouvreau L, Joosten R, Hinz SW, Gruppen H, Schols HA. Chrysosporium lucknowense $\mathrm{C} 1$ arabinofuranosidases are selective in releasing arabinose from either single or double substituted xylose residues in arabinoxylans. Enzyme Microb Technol. 2011;48(4-5):397-403.

14. Sakamoto T, Kawasaki H. Purification and properties of two type-B a-Larabinofuranosidases produced by Penicillium chrysogenum. Biochim Biophys Acta. 2003;1621(2):204-10.
15. Sakamoto T, Inui M, Yasui K, Hosokawa S, Ihara H. Substrate specificity and gene expression of two Penicillium chrysogenum a-L-arabinofuranosidases (AFQ1 and AFS1) belonging to glycoside hydrolase families 51 and 54. Appl Microbiol Biotechnol. 2013;97(3):1121-30.

16. You S, Tu T, Zhang L, Wang Y, Huang H, Ma R, Shi P, Bai Y, Su X, Lin Z, Luo $H, Y a o$ B. Improvement of the thermostability and catalytic efficiency of a highly active $\beta$-glucanase from Talaromyces leycettanus JCM12802 by optimizing residual charge-charge interactions. Biotechnol Biofuels. 2016:9:124

17. Liu W, Tu T, Gu Y, Wang Y, Zheng F, Zheng J, Wang Y, Su X, Yao B, Luo H. Insight into the thermophilic mechanism of a glycoside hydrolase family 5 ß-mannanase. J Agric Food Chem. 2019;67(1):473-83.

18. Wang $X$, Huang $H$, Xie X, Ma R, Bai Y, Zheng F, You S, Zhang B, Xie H, Yao $\mathrm{B}$, Luo $\mathrm{H}$. Improvement of the catalytic performance of a hyperthermostable GH10 xylanase from Talaromyces leycettanus JCM12802. Bioresour Technol. 2016:222:277-84

19. Li Y, Wang Y, Tu T, Zhang D, Ma R, You S, Wang X, Yao B, Luo H, Xu B. Two acidic, thermophilic $\mathrm{GH} 28$ polygalacturonases from Talaromyces leycettanus JCM 12802 with application potentials for grape juice clarification. Food Chem. 2017:237:997-1003.

20. Li X, Tu T, Yao B, Xie X, Luo H. A novel bifunctional xylanase/cellulase TCXyn10A from Thermoascus crustaceus JCM12803. Chin J Biotechnol. 2018;34(12):1996-2006

21. He Y, Chang C, Li P, Han X, Li H, Fang S, Chen J, Ma X. Thermal decomposition and kinetics of coal and fermented cornstalk using thermogravimetric analysis. Bioresour Technol. 2018;259:294-303.

22. Sørensen HR, Jørgensen $\mathrm{CT}$, Hansen $\mathrm{CH}$, Jørgensen $\mathrm{Cl}$, Pedersen S, Meyer AS. A novel GH43 a-L-arabinofuranosidase from Humicola insolens: mode of action and synergy with GH51a-L-arabinofuranosidases on wheat arabinoxylan. Appl Microbiol Biotechnol. 2006;73(4):850-61.

23. Fritz M, Ravanal MC, Braet C, Eyzaguirre J. A family 51 a-Larabinofuranosidase from Penicillium purpurogenum: purification, properties and amino acid sequence. Mycol Res. 2008;112(Pt 8):933-42.

24. Hashimoto K, Yoshida M, Hasumi K. Isolation and characterization of CcAbf62A, a GH62 a-L-arabinofuranosidase, from the Basidiomycete Coprinopsis cinerea. Biosci Biotechnol Biochem. 2011;75:342-5.

25. Yang W, Bai Y, Yang P, Luo H, Huang H, Meng K, Shi P, Wang Y, Yao B. A novel bifunctional GH51 exo-a-L-arabinofuranosidase/endo-xylanase from Alicyclobacillus sp. A4 with significant biomass-degrading capacity. Biotechnol Biofuels. 2015:8:197.

26. Bouraoui $H$, Desrousseaux ML, loannou E, Alvira P, Manaï M, Rémond C. Dumon C, Fernandez-Fuentes N, O'Donohue MJ. The GH51 a-Larabinofuranosidase from Paenibacillus sp. THS1 is multifunctional, hydrolyzing main-chain and side-chain glycosidic bonds in heteroxylans. Biotechnol Biofuels. 2016;9:140

27. Yang $X$, Shi P, Ma R, Luo H, Huang H, Yang P, Yao B. A new GH43 a-arabinofuranosidase from Humicola insolens $Y 1$ : biochemical characterization and synergistic action with a xylanase on xylan degradation. Appl Biochem Biotechnol. 2015;175(4):1960-70.

28. Saleh MA, Han WJ, Lu M, Wang B, Li H, Kelly RM, Li FL. Two distinct a-L-arabinofuranosidases in Caldicellulosiruptor species drive degradation of arabinose-based polysaccharides. Appl Environ Microbiol. 2017:83(13):e00574-17.

29. Mathew S, Aronsson A, Karlsson EN, Adlercreutz P. Xylo- and arabinoxylooligosaccharides from wheat bran by endoxylanases, utilisation by probiotic bacteria, and structural studies of the enzymes. Appl Microbiol Biotechnol. 2018;102(7):3105-20.

30. Tu T, Bai Y, Luo H, Ma R, Wang Y, Shi P, Yang P, Meng K, Yao B. A novel bifunctional pectinase from Penicillium oxalicum SX6 with separate pectin methylesterase and polygalacturonase catalytic domains. Appl Microbiol Biotechnol. 2014;98(11):5019-28.

31. Toda H, Nagahata N, Amano Y, Nozaki K, Kanda T, Okazaki M, Shimosaka M. Gene cloning of cellobiohydrolase II from the white rot fungus Irpex lacteus MC-2 and its expression in Pichia pastoris. Biosci Biotechnol Biochem. 2008;72(12):3142-7.

32. Wang $\mathrm{C}$, Luo $\mathrm{H}$, Niu $\mathrm{C}$, Shi $\mathrm{P}$, Huang $\mathrm{H}$, Meng $\mathrm{K}$, Bai Y, Wang $\mathrm{K}$, Hua $\mathrm{H}$, Yao B. Biochemical characterization of a thermophilic $\beta$-mannanase from Talaromyces leycettanus JCM12802 with high specific activity. Appl Microbiol Biotechnol. 2015:99(3):1217-28.

33. Miller GL. Use of dinitrosalicylic acid reagent for determination of reducing sugar. Anal Chem. 1959;31(3):426-8. 
34. Tu T, Li Y, Luo Y, Wang Z, Wang Y, Luo H, Yao B. A key residue for the substrate affinity enhancement of a thermophilic endo-polygalacturonase revealed by computational design. Appl Microbiol Biotechnol. 2018;102(10):4457-66.

\section{Publisher's Note}

Springer Nature remains neutral with regard to jurisdictional claims in published maps and institutional affiliations.
Ready to submit your research? Choose BMC and benefit from:

- fast, convenient online submission

- thorough peer review by experienced researchers in your field

- rapid publication on acceptance

- support for research data, including large and complex data types

- gold Open Access which fosters wider collaboration and increased citations

- maximum visibility for your research: over $100 \mathrm{M}$ website views per year

At BMC, research is always in progress.

Learn more biomedcentral.com/submissions 